\title{
Microbial Photoelectrotrophic Denitrification as a Sustainable and Efficient Way for Reducing Nitrate to Nitrogen
}

\author{
Hao-Yi Cheng, ${ }^{\dagger}$ Xia-Di Tian, ${ }^{\dagger,}$ Chuan-Hao Li, ${ }^{\S}$ Shu-Sen Wang, ${ }^{\dagger, \ddagger}$ Shi-Gang Su, ${ }^{\dagger, \ddagger}$ Hong-Cheng Wang,
} Bo Zhang, Hafiz Muhammad Adeel Sharif, ${ }^{\dagger} \dagger, \ddagger$ and Ai-Jie Wang ${ }^{\dagger},+\ddagger 0$

${ }^{\dagger}$ Key Laboratory of Environmental Biotechnology, Research Center for Eco-Environmental Sciences, Chinese Academy of Sciences, No. 18 Shuangqing Road, Haidian District, Beijing 100085, China

${ }^{\ddagger}$ University of Chinese Academy of Sciences, No. 19 Yuquan Road, Shijingshan District, Beijing 100049, China

${ }^{\S}$ School of Environmental Science and Engineering, Sun Yat-Sen University, East Campus, No. 135 Waihuan Road, Daxuecheng District, Guangzhou 510006, China

Supporting Information

ABSTRACT: Biological removal of nitrate, a highly concerning contaminant, is limited when the aqueous environment lacks bioavailable electron donors. In this study, we demonstrated, for the first time, that bacteria can directly use the electrons originated from the photoelectrochemical process to carry out the denitrification. In such photoelectrotrophic denitrification (PEDeN) systems (denitrification biocathode coupling with $\mathrm{TiO}_{2}$ photoanode), nitrogen removal was verified solely relying on the illumination dosing without consuming additional chemical reductant or electric power. Under the UV illumination (30 $\mathrm{mW} \cdot \mathrm{cm}^{-2}$, wavelength at $\left.380 \pm 20 \mathrm{~nm}\right)$, nitrate reduction in PEDeN apparently followed the first-order kinetics with a constant of $0.13 \pm 0.023 \mathrm{~h}^{-1}$. Nitrate was found to be almost

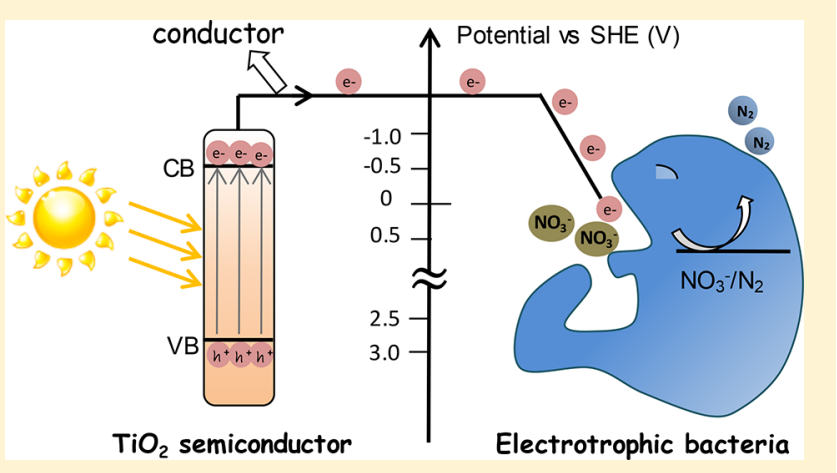
completely converted to nitrogen gas at the end of batch test. Compared to the electrotrophic denitrification systems driven by organics (OEDeN, biocathode/acetate consuming bioanode) or electricity (EEDeN, biocathode/abiotic anode), the denitrification rate in PEDeN equaled that in OEDeN with a COD/N ratio of 9.0 or that in EEDeN with an applied voltage at $2.0 \mathrm{~V}$. This study provides a sustainable technical approach for eliminating nitrate from water. PEDeN as a novel microbial metabolism may shed further light onto the role of sunlight played in the nitrogen cycling in certain semiconductive and conductive minerals-enriched aqueous environment.

\section{INTRODUCTION}

Nitrate is one of the most concerning contaminants due to its ubiquity and adverse effects on human health and ecosystem. ${ }^{1}$ Autotrophic denitrification, the biological process of transforming nitrate to the innocuous nitrogen gas with inorganic electron donors, has received great attention in past decades. ${ }^{2,3}$ Because the autotrophic denitrification does not rely on the presence of organic matter, it is particularly attractive during the treatment of drinking water and the secondary effluent of wastewater treatment plants, in which the organic form of electron donors is typically lacking., ${ }^{4,5}$ Compared to the heterotrophic denitrification by adding organic electron donors, autotrophic denitrification is suggested to be more cost effective and it avoids the risk of secondary organic pollution. ${ }^{2}$

In autotrophic denitrification, hydrogen is the most frequently used electron donor due to its innocuous nature. ${ }^{6}$ However, the direct use of hydrogen gas may lead to safety issues and suffer from a low $\mathrm{H}_{2}$ utilization efficiency due to its low water solubility. Therefore, denitrification using electrodes, which generates hydrogen through hydrogen evolution reactions in situ, was developed as an alternative approach. ${ }^{2,7}$ After that bacteria was found to directly receive electrons from the electrode for denitrification without hydrogen as an electron mediator (here defined as the electrotrophic denitrification, EDeN). ${ }^{8}$ In this process, $\mathrm{EDeN}$ gains the benefit of less energy loss because of its occurrence at a more positive potential compared to the hydrogen evolution. ${ }^{8}$ In the case of the denitrification driven by the electrode (as the cathode), another electrode has to be coupled as the anode. Oxygen evolution is the main anodic reaction in most cases with the theoretical occurrence potential at $0.82 \mathrm{~V}$ (versus standard hydrogen electrode, SHE, at $\mathrm{pH} 7$ ). Because this potential is more positive than that of nitrate reduction (i.e., $E_{\mathrm{NO} 3-/ \mathrm{NO} 2-}=0.43 \mathrm{~V}$ vs $\mathrm{SHE}$ at $\mathrm{pH} 7$ ), electric energy input is required. Alternatively, a microbial catalytic anode system can

Received: May 29, 2017

Revised: October 8, 2017

Accepted: October 13, 2017

Published: October 13, 2017 

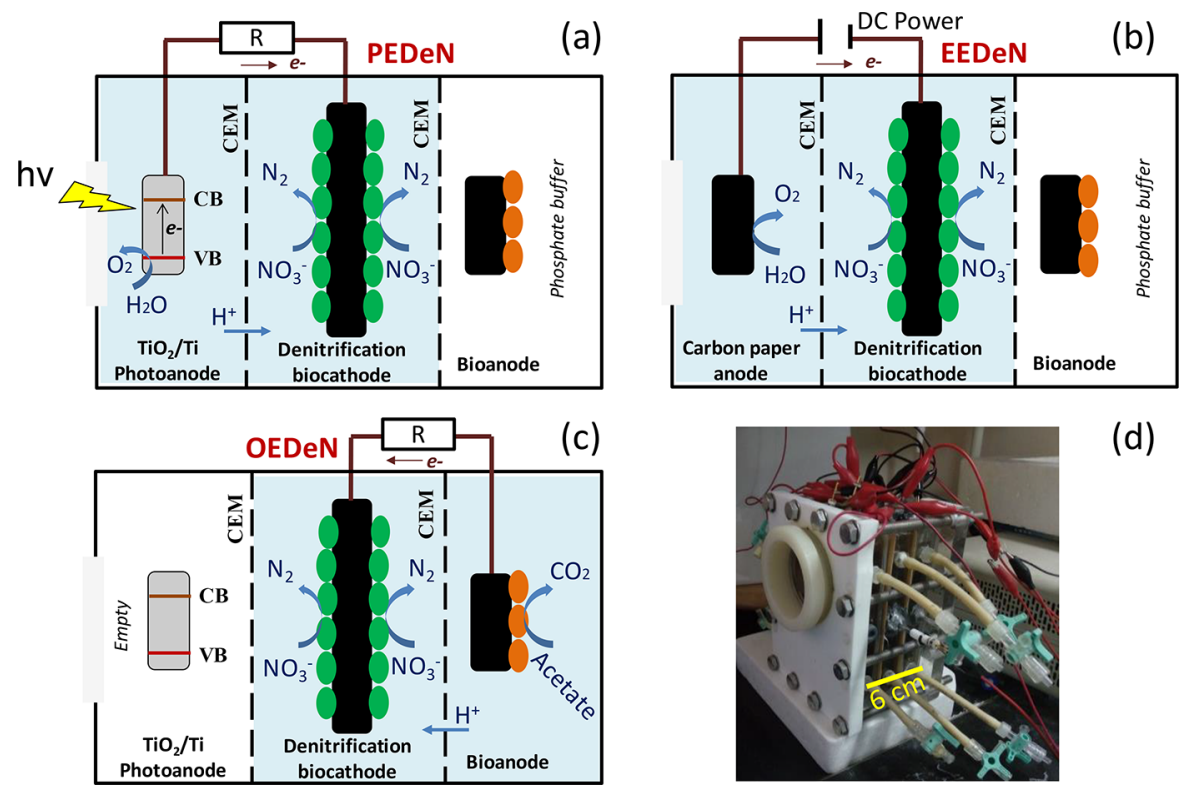

(d)

Figure 1. Schematic diagrams of operating the three-chamber reactors as (a) a photoelectrotrophic denitrification (PEDeN) system, (b) an electricity driven electrotrophic denitrificaton (EEDeN) system, and (c) an organic-driven electrotrophic denitrificaton (OEDeN) system. (d) Photograph of the three-chamber reactor used in this study. CEM: cation exchange membrane.

be employed without the power supply, where biodegradable organics are oxidized by anode respiration bacteria at a more negative potential (e.g., the typical $E_{\text {acetate } / \mathrm{HCO}^{-}}$is $-0.28 \mathrm{~V}$ vs SHE at $\mathrm{pH} 7$ ) compared to the nitrate reduction. 9,10

Solar energy is considered to be a clean and sustainable energy source. Conversion of solar energy to chemical energy is realized with the help of a semiconductor, which provides the reducing and oxidizing power through the photoexcited electrons and holes under illumination, respectively. ${ }^{11}$ To date, $\mathrm{TiO}_{2}$ is the most intensively studied semiconductor since it is inexpensive and easily synthesized. ${ }^{12}$ Photocatalytic nitrate reduction has been reported in $\mathrm{TiO}_{2}$ systems, ${ }^{13,14}$ but the selectivity of $\mathrm{N}_{2}$ formation is low, and the over reduction of nitrate to ammonium ions is particularly undesired. Although the selectivity is improved by doping other metals, such as $\mathrm{TiO}_{2} / \mathrm{Pt}, \mathrm{TiO}_{2} / \mathrm{Ag}, \mathrm{TiO}_{2} / \mathrm{Ni}-\mathrm{Cu}$, etc., ${ }^{13,15}$ the cost of the catalysts would inevitably increase, while the formation of ammonium is still not negligible. ${ }^{15}$ On the contrary, microbial denitrification usually has high selectivity. Regarding the EDeN, ammonium formation was reported to be at a very low level or even not detected. ${ }^{8,16}$ Considering that the conduction band of $\mathrm{TiO}_{2}(-0.5 \mathrm{~V}$ vs SHE at $\mathrm{pH} 7)$ lies at an energy level that is noticeably higher than that of nitrate reduction, the photoexcited electrons should have energy high enough to drive EDeN without additional energy input, such as power supply as in the previous study. ${ }^{17}$ Therefore, we hypothesize that combining the $\mathrm{TiO}_{2}$ semiconductor system with the EDeN will gain a high selectivity for reducing nitrate to $\mathrm{N}_{2}$, and the occurrence of this process can solely rely on the illuminating dose. In such a novel photoelectrotrophic denitrification (PEDeN) process, the generation of photoelectrons is independent of the presence of organics, which makes the PEDeN particularly promising in the denitrification under organics-limited conditions. To the best of our knowledge, the proposed PEDeN here has not been verified yet.

Herein, the PEDeN was developed by constructing a photoelectrochemical cell, where a denitrification biocathode was connected to a $\mathrm{TiO}_{2}$ photoanode without voltage supply
(Figure 1a). The objectives of this study are (i) to demonstrate the PEDeN is capable of efficiently reducing nitrate to nitrogen without additional reductant and energy input and (ii) to understand the performance of PEDeN by comparing with the already established electricity driven EDeN system (EEDeN, also known as electrochemical bioreactor of denitrification, Figure $1 \mathrm{~b}$ ) and organics-driven EDeN system (OEDeN, also known as denitrification microbial fuel cell, Figure 1c).

\section{MATERIALS AND METHODS}

Reactor Construction. The reactor was designed as three chambers which were separated by cation exchange membranes (Ultrex CMI-7000, Membranes International, U.S.). The cathode chamber was arranged in the middle, while the two side chambers were set as photoanode chamber and bioanode chamber (Figure 1). The side plate of the photoanode chamber was equipped with a quartz glass window $(6 \mathrm{~cm}$ in diameter) that allowed the light passage. The $\mathrm{TiO}_{2} / \mathrm{Ti}$ plate (surface area $\left.=16 \mathrm{~cm}^{2}\right)$, graphite granules $(3-4 \mathrm{~mm}$ in diameter), and carbon brush were employed as the electrode materials in each chamber as the photoanode, biocathode, and bioanode, respectively. The working volumes of these three chambers were 230,100 , and $180 \mathrm{~mL}$, respectively. The biocathode was connected to the photoanode in the PEDeN test while to the bioanode in the OEDeN test. A $10 \Omega$ resistance was inserted into the electric circuit in series to allow the sampling of current. In the case of the EEDeN test, the $\mathrm{TiO}_{2} / \mathrm{Ti}$ plate was replaced by a piece of carbon paper with the same projected area. The biocathode at this moment was connected to the carbon paper electrode through $\mathrm{dc}$ power. The operation manners of this three-chamber reactor as PEDeN, OEDeN, and EEDeN are schematically illustrated in Figure 1. Each chamber was equipped with a $\mathrm{Ag} / \mathrm{AgCl}$ reference electrode (saturated $\mathrm{KCl}, 197 \mathrm{mV}$ vs standard hydrogen electrode, SHE) to measure the potentials of the corresponding electrodes.

Preparation of $\mathrm{TiO}_{2} / \mathrm{Ti}$ Photoanode and Denitrification Biocathode. The $\mathrm{TiO}_{2} / \mathrm{Ti}$ photoanode was prepared by a modified sol-gel and spin-coating method as described 

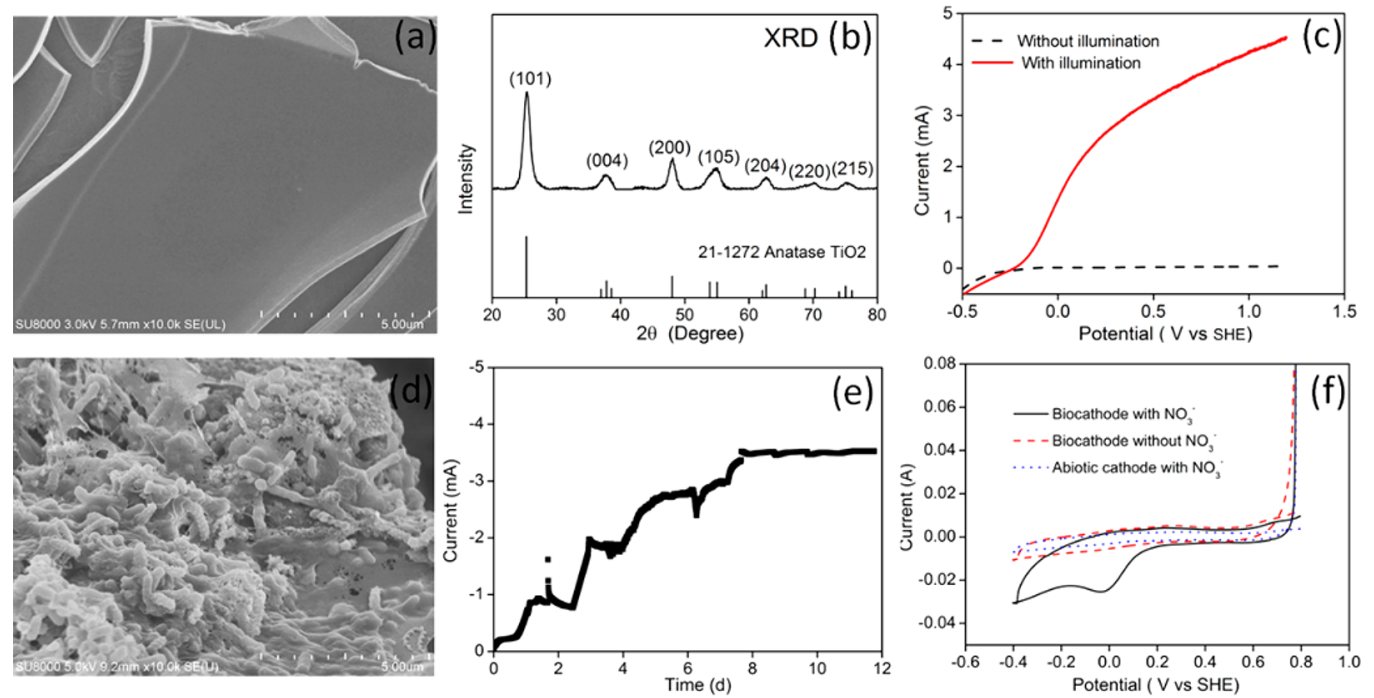

Figure 2. Characterization of the $\mathrm{TiO}_{2} / \mathrm{Ti}$ photoanode and denitrification biocathode: (a) field emission scanning electron microscope (FESEM) images of photoanode and (d) biocathode, (b) X-ray diffraction (XRD) pattern of the $\mathrm{TiO}_{2}$ coating at photoanode, (c) representative linear scan voltammogram of photoanode with a scan rate at $10 \mathrm{mV} \cdot \mathrm{s}^{-1}$, (e) representative current profile of biocathode during acclimation, and (f) representative cyclic voltammogram (first cycle) of biocathode and abiotic cathode with a scan rate at $0.5 \mathrm{mV} \cdot \mathrm{s}^{-1}$.

previously by Dong et al. ${ }^{18}$ Briefly, $38 \mathrm{~mL}$ of solution A $(76 \%$ $\mathrm{C}_{2} \mathrm{H}_{5} \mathrm{OH}, 9 \% \mathrm{H}_{2} \mathrm{O}$, and $\left.15 \% \mathrm{CH}_{3} \mathrm{COOH}\right)$ was added dropwise to $62 \mathrm{~mL}$ of solution $\mathrm{B}\left(54 \% \mathrm{Ti}\left(\mathrm{OC}_{4} \mathrm{H}_{9}\right)_{4}\right.$ and $\left.46 \% \mathrm{C}_{2} \mathrm{H}_{5} \mathrm{OH}\right)$. Nitric acid was then added in the mixture for adjusting the $\mathrm{pH}$ to $1-2$. This solution was further kept at room temperature for $24 \mathrm{~h}$ for the sol-gel aging. Subsequently, the prepared sol-gel was spin coated in three layers on the Ti sheet and calcined for $2 \mathrm{~h}$ at $500{ }^{\circ} \mathrm{C}$ in a furnace (KSL-1200X, MTI KJ Group, Hefei, China). The denitrification biocathode was acclimated in the above-mentioned three-chamber reactor by coupling a bioanode which was precultured in a separate bioelectrochemical system using acetate as the electron donor. The active sludge obtained from a local domestic wastewater treatment plant was used as the inoculum for the biocathode. The modified $\mathrm{M} 9$ nutrient medium $(\mathrm{pH}=7)$ amended by $10 \mathrm{~mL}$. $\mathrm{L}^{-1}$ Wolfe's trace elements and $\mathrm{KNO}_{3}\left(\mathrm{NO}_{3}-\mathrm{N}=35 \mathrm{mg} \cdot \mathrm{L}^{-1}\right)$ was employed as the catholyte, while the same solution but replacing the $\mathrm{KNO}_{3}$ by $500 \mathrm{mg} \cdot \mathrm{L}^{-1}$ sodium acetate was used as the anolyte. Both of these solutions were prior deoxygenated using argon gas (purity > 99.9\%) and then continuously fed into the chambers with a flow rate of $120 \mathrm{~mL} \cdot \mathrm{day}^{-1}$. The cathode and the anode were connected through a $10 \Omega$ resistance. Once the current generation was observed and kept stable, the acclimation of denitrification biocathode was considered to be successful.

Operation. For the PEDeN, OEDeN, and EEDeN tests, the reactors were operated as batch-fed mode. In the PEDeN test, the denitrification biocathode was coupled with the $\mathrm{TiO}_{2} / \mathrm{Ti}$ photoanode. The cathode chamber was fed with the same solution as in the acclimation stage except the inoculum, while the anode chamber was just fed with the modified M9 nutrient medium. A xenon lamp (PLS-SXE300UV, PerfectLight, Beijing, China) was used as the light source and equipped with a 380 $\mathrm{nm}( \pm 20 \mathrm{~nm})$ bandpass filter (DT380, PerfectLight, Beijing, China). The intensity of the illumination was adjusted to be 30 , 45 , and $60 \mathrm{~mW} \cdot \mathrm{cm}^{-2}$, respectively. In order to understand the effect of the illumination on the denitrification, the xenon lamp was switched on/off to provide a light/dark condition. In parallel, the reactors equipped with the abiotic cathode were set to explore the role of bacteria in denitrification. For EEDeN and OEDeN tests, the experiments were carried out under dark conditions with the modified M9 nutrient medium and that amended by sodium acetate $\left(0,68,135,270,405,540 \mathrm{mg} \cdot \mathrm{L}^{-1}\right)$ as the anolyte, respectively. In PEDeN and EEDeN tests, the bioanode chamber was just filled with phosphate-buffered solution to exclude the possibility of acetate diffusing to the biocathode chamber. All of the above-mentioned experiments were conducted with replicate reactors in a temperaturecontrolled laboratory $\left(\sim 28{ }^{\circ} \mathrm{C}\right)$. For each condition, the reactors were operated at least 3 runs.

Analysis and Calculation. The $\mathrm{TiO}_{2} / \mathrm{Ti}$ photoanode and denitrification biocathode were electrochemically characterized through linear scan voltammetry (LSV) and cyclic voltammetry $(\mathrm{CV})$, respectively, using an electrochemical working station (model-660D, CHI Instruments Inc. Shanghai, China). The LSVs for photoanodes were performed from the potential from -0.5 to $1.2 \mathrm{~V}$ (versus SHE) with a scan rate of $10 \mathrm{mV} \cdot \mathrm{s}^{-1}$. The $\mathrm{CVs}$ for denitrification biocathode were carried out with a scan rate of $0.5 \mathrm{mV} \cdot \mathrm{s}^{-1}$ in the potential window between -0.4 and $0.8 \mathrm{~V}$ (versus SHE). The morphology of the $\mathrm{TiO}_{2} / \mathrm{Ti}$ photoanode and cathode biofilm were examined by a field emission scanning electron microscope (FESEM, SU8020 Hitachi, Ltd., Japan). The crystallographic structure of the $\mathrm{TiO}_{2}$ thin film was characterized by an X-ray diffraction (PANalytical PW 3050 Philips X'pert Pro). The electrode potential and the current flowing through the sampling resistance were recorded every $10 \mathrm{~min}$ by a data acquisition system (model 2700, Keithley Instruments Inc., U.S.). The $\mathrm{NO}_{3}{ }^{-}$and $\mathrm{NO}_{2}{ }^{-}$were measured using an ion chromatograph (883 Basic IC plus. Metrohm, Switzerland) equipped with a Metrosep A Supp 5-250 column (Metrohm, Switzerland). The concentration of $\mathrm{N}_{2} \mathrm{O}$ in the headspace of cathode chamber $(\sim 10 \mathrm{~mL})$ was determined using gas chromatographic mass spectrometry as described in Cheng et al. ${ }^{19}$ The $\mathrm{N}_{2} \mathrm{O}$ concentration in the liquid phase was calculated according to that in the gas phase using Henry's law. The reported aqueous $\mathrm{N}_{2} \mathrm{O}$ concentration was modified by adding those $\mathrm{N}_{2} \mathrm{O}$ in the gas phase. The $\mathrm{NH}_{4}^{+}$ions were detected according to the 
Nessler reagent colorimetry method. The sodium acetate was measured by a high-performance liquid chromatography (HPLC, e2695, Waters Co., U.S.) equipped with a Aminex HPX-87 column (Bio-Rad Laboratories, Inc., U.S.) at a wavelength of $210 \mathrm{~nm}$. The current efficiency for denitrification at cathode was calculated as the ratio of the theoretical numbers of electron transfer based on the transformation of nitrogen compounds to the observed numbers of electron transfers in the batch-fed experiments

$$
\text { current efficiency }=\frac{\left[5 \times\left(C_{\mathrm{NO}_{3}^{-}-\mathrm{N}}^{0}-C_{\mathrm{NO}_{2}^{-}-\mathrm{N}}^{t}-C_{\mathrm{N}_{2} \mathrm{O}-\mathrm{N}}^{t}\right)+2 C_{\mathrm{NO}_{2}^{-}-\mathrm{N}}^{t}+4 C_{\mathrm{N}_{2} \mathrm{O}-\mathrm{N}}^{t}\right] \times V \times F}{\int_{0}^{t} I \mathrm{~d} t}
$$

where $C_{\mathrm{NO}_{3}^{-}-\mathrm{N}}^{0}(\mathrm{mM})$ is the initial nitrate nitrogen concentration. $C_{\mathrm{NO}_{2}^{-}-\mathrm{N}}^{t}(\mathrm{mM})$ and $C_{\mathrm{N}_{2} \mathrm{O}-\mathrm{N}}^{t}(\mathrm{mM})$ are the concentrations of nitrite nitrogen and nitrous oxide nitrogen, respectively, at $t(\mathrm{~s})$ time. $V(\mathrm{~L})$ is the working volume of the cathode chamber. $I(\mathrm{~mA})$ is the recorded current. $F$ is Faraday's constant $\left(96485 \mathrm{C} \cdot \mathrm{mol}^{-1}\right)$. Five is the electron transfer number of nitrate to nitrogen gas. Two is the electron transfer number of nitrate to nitrite. Four is the electron transfer number of nitrate to nitrous oxide.

\section{RESULTS}

Characterization of $\mathrm{TiO}_{2}$ Photoanode and Denitrification Biocathode. As shown in Figure 2a, the sol-gel formed a film of $\mathrm{TiO}_{2}$ on $\mathrm{Ti}$ sheets. This $\mathrm{TiO}_{2}$ film has visible cracks on it, which was consistent with the previous studies and would likely provide a large reaction surface. ${ }^{20,21}$ According to the $\mathrm{XRD}$ analysis (Figure 2b), the crystallographic structure of the $\mathrm{TiO}_{2}$ is indexed as the anatase phase. Current generation as a function of electrode potential is shown as in Figure 2c. Negligible photocurrent was observed under dark condition, while photocurrent was produced when the electrode potential was positively scanned to $-0.25 \mathrm{~V}$ vs SHE and finally reached $4.5 \mathrm{~mA}$ at $1.2 \mathrm{~V}$ vs SHE (scan rate of $10 \mathrm{mV} \cdot \mathrm{s}^{-1}$ ). Since the performance of light-to-current conversion could be varied among individual prepared photoanode (data not shown), only those photoanodes with similar photoelectrochemical behavior were used for the following experiments.

In terms of the acclimation of denitrification biocathode (Figure 2e), the current generation presents a lag time of 2 days and then rapidly increases from day 2 to day 8. Subsequently, the current kept stable for 4 days at around $-3.5 \mathrm{~mA}$. These results suggest the successful development of denitrification biocathode. The denitrification biocathode was then electrochemically characterized by the $\mathrm{CV}$ test with a scan rate at 0.5 $\mathrm{mV} \cdot \mathrm{s}^{-1}$. As shown in Figure $2 \mathrm{f}$, an obvious reduction peak is observed in the biocathode $\mathrm{CV}$ with the presence of nitrate, which has an onset potential and peak potential at around 0.15 and $0 \mathrm{~V}$ (versus SHE), respectively. As the control, CV of abiotic cathode was also performed, which showed negligible faradaic current, clearly indicating the peak related to nitrate reduction in the biocathode $\mathrm{CV}$ is a result of microbial catalysis. At the end of the denitrification biocathode acclimation, the graphite granules were characterized by SEM, which showed the coverage of the biofilm (Figure 2d).

Denitrification Driven by Light. Nitrate concentration as well as the photocurrent was monitored in the ON-OFF intermittent illumination test. As shown in Figure 3a, the nitrate reduction of the PEDeN system is coordinated with the current generation and only observed under illumination. This result clearly reveals the nitrate reduction is capable of being driven by light. A control test by coupling the photoanode with an abiotic cathode was carried out under the same ON-OFF intermittent illumination condition, in which the dosing of illumination did not arouse current generation. As a result, the change of nitrate concentration at the cathode chamber was negligible. These observations confirm that the nitrate reduction in PEDeN system depends upon both the illumination dosing at photoanode and the microbial activity at cathode.

Upon illumination, the reduction of nitrate followed the pseudo-first-order reaction with a kinetic constant of $0.13 \pm$ $0.023 \mathrm{~h}^{-1}(n=4$, fitted according to Figure $3 \mathrm{~b})$. During the nitrate reduction, the accumulations of nitrite and nitrous oxide were observed, which is consistent with the previous works. ${ }^{22,23}$ These denitrification intermediates depleted after approaching a maximum concentration. In all batch tests, ammonium was always below the detection limit, which is $0.02 \mathrm{mg} \cdot \mathrm{L}^{-1}$ (Nessler reagent colorimetry method), indicating the nitrate was selectively reduced to nitrogen. As shown in Figure 3c, initially photocurrent keeps at about $1.5 \mathrm{~mA}$ and then declines after 12 $h$. With the exhaustion of oxidized nitrogen, the photocurrent declined to zero. The current efficiency at the cathode was calculated, and its value for denitrification was $97.02 \pm 1.4 \%(n$ $=4)$ at the end of the batch tests. Cathode potential during the experiments fell into the range between 0.05 and $-0.03 \mathrm{~V}$ (versus SHE), which is more positive than the theoretical potential of hydrogen evolution and consequently confirms the denitrification does not rely on the hydrogen as the electron mediator. In addition to hydrogen evolution, other side reactions, such as the $\mathrm{CO}_{2}$ reduction to methane or organics, can be also excluded because they were thermodynamically unfavorable (i.e., the standard potentials for $\mathrm{CO}_{2}$ reduction to methane and organics at $\mathrm{pH} 7$ are about -0.24 and $-0.28 \mathrm{~V}$ vs SHE, respectively, which are more negative to the cathode working potential of PEDeN). Therefore, the small number of electron loss here is likely due to the consumption by microbial growth.

As mentioned above, the photocurrent kept stable but did not decline with the depletion of oxidized nitrogen compounds during the initial $12 \mathrm{~h}$. This suggests the rate-limiting factor of denitrification in the current set of PEDeN did not come from the cathode side but more likely was due to the low electrons providing capability of the photoanode. In order to get insight into this issue, PEDeN was further tested under higher illumination intensities (45 and $60 \mathrm{~mW} \cdot \mathrm{cm}^{-2}$ ). As shown in Figure S1, both the photocurrent and denitrification rate were enhanced with increasing illumination intensity. When the illumination density got to $60 \mathrm{~mW} \cdot \mathrm{cm}^{-2}$, the denitrification rate constant reached $0.15 \pm 0.02 \mathrm{~h}^{-1}(n=2)$, which was $36.36 \%$ higher than that observed under $30 \mathrm{~mW} \cdot \mathrm{cm}^{-2}$ illumination. Compared to the PEDeN operated at lower illumination intensity, no substantial difference of the current efficiency was observed at higher illumination intensity $(96.86 \pm 1.8 \%, n=4$, 

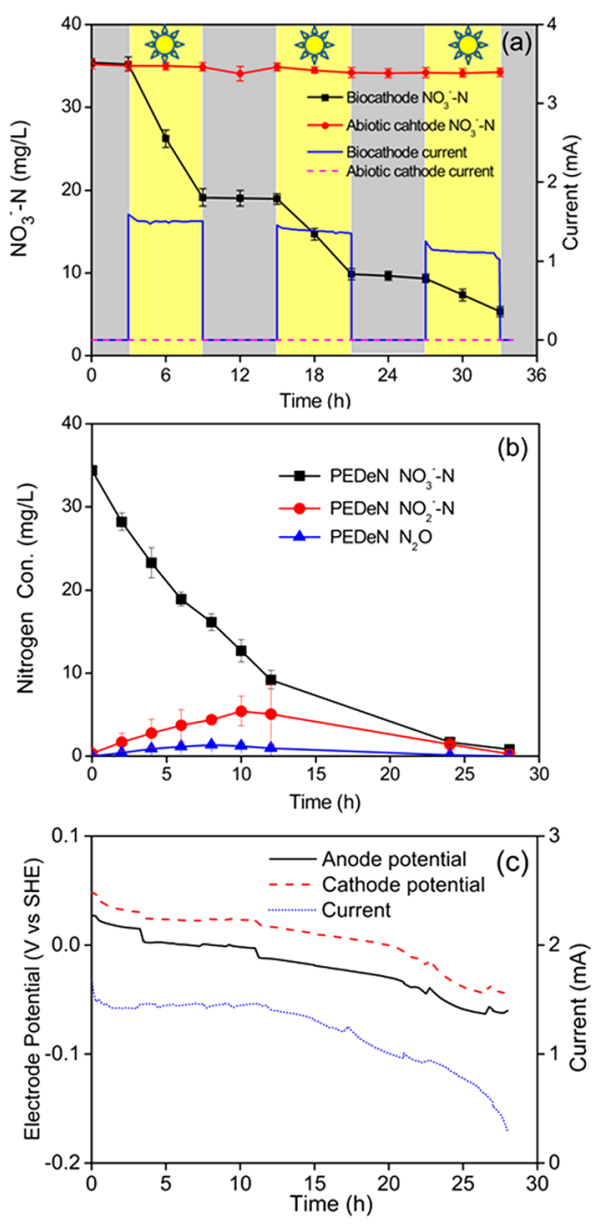

Figure 3. (a) Variations of nitrate $(n=2)$ and the representative current profile in the ON-OFF intermittent illumination tests, (b) time course of the changes of nitrogen oxide compounds $(n=4)$, and (c) representative current and electrode potentials in the fed-batch test of photoelectrotrophic (PEDeN) systems.

$\left.60 \mathrm{~mW} \cdot \mathrm{cm}^{-2}\right)$. Under high-illumination intensity condition, the variation of photocurrent followed identical trends as that of total nitrogen, indicating the denitrification rate-limiting factor switched to the cathode side (i.e., controlled by the available oxidized nitrogen compounds serving as electron acceptors).

PEDeN verus OEDeN and EEDeN. As the reactors employed in this study have a three-chamber configuration, the denitrification performance in PEDeN, OEDeN, and EEDeN can be compared using the same denitrification biocathode. In the case of $\mathrm{OEDeN}$, the denitrification biocathode was coupled by an acetate-consuming bioanode. As shown in Figure 4a, the performance of OEDeN is sensitive to the $\mathrm{COD} / \mathrm{N}\left(\mathrm{g} \mathrm{COD} / \mathrm{g} \mathrm{NO}_{3}{ }^{-}-\mathrm{N}\right)$ ratio. The total nitrogen (TN) removal efficiency of OEDeN can be comparable to that of PEDeN only at a COD/N ratio higher than 9.0. The number of electrons transferred, in terms of coulombs, to biocathode is plotted in Figure 4a, which also shows a positive correlation to the $\mathrm{COD} / \mathrm{N}$ ratio, indicating the inferior $\mathrm{TN}$ removal efficiency of OEDeN at low $\mathrm{COD} / \mathrm{N}$ ratio was due to the lack of electron donors. The theoretical $\mathrm{COD} / \mathrm{N}$ ratio for completely converting nitrate to nitrogen gas should be 2.86 in OEDeN based on the stoichiometry. However, the electron equivalents could be lost for the microbial assimilation or competitive methanogenesis at the bioanode. ${ }^{24}$ Thus, the observed COD/N can be always higher than the theoretical value. The COD/N
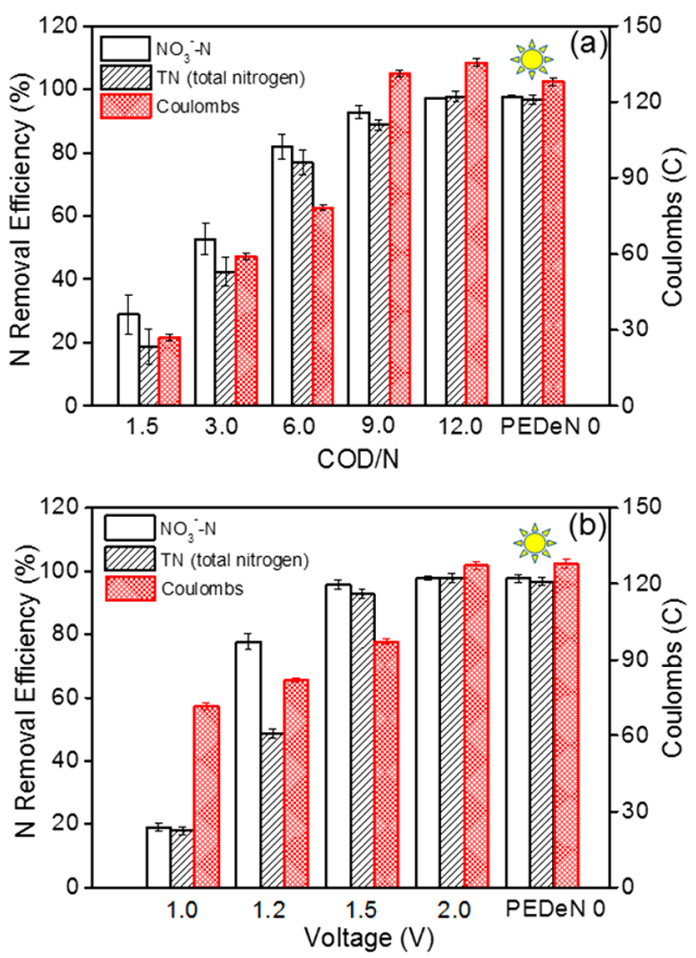

Figure 4. Denitrification performance in different electrotrophic denitrification (EDeN) systems. (a) Organic-driven electrotrophic denitrification $(\mathrm{OEDeN})$ systems under different $\mathrm{COD} / \mathrm{N}$ (g chemical oxygen demand $/ \mathrm{g} \mathrm{NO}_{3}{ }^{-}-\mathrm{N}$ ) ratio conditions vs photoelectrotrophic denitrification (PEDeN) systems without organic electron donor. (b) Electricity driven electrotrophic denitrification (EEDeN) systems under different applied voltages conditions vs PEDeN without voltage. Errors: $n=4$.

ratio obtained in our study falls in the same order of magnitude as that reported by others $\left(4.5-16 \mathrm{~g}\right.$ COD to $\left.\mathrm{g} \mathrm{NO}_{3}{ }^{-}-\mathrm{N}\right) .^{10,25}$

In the EEDeN test, the $\mathrm{TiO}_{2} / \mathrm{Ti}$ photoanode was replaced by a piece of carbon paper with the same projected area. Without the applied voltage, the current generation was negligible (Figure S2b). This is because the potential of electrochemical oxygen evolution is more positive than that of the nitrate reduction. Although carbon dioxide formation at a carbonbased electrode is thermodynamically possible at more negative potential $(<-0.214 \mathrm{~V}$ vs SHE at $\mathrm{pH} 7)$, the high overpotential of this reaction may prevent it from driving the nitrate reduction at the cathode. ${ }^{26}$ Actually, when the anode potential attained about $1.02 \mathrm{~V}$ vs SHE here (at applied voltage of $1.0 \mathrm{~V}$ ), the observed initial current was only $0.6 \mathrm{~mA}$, which was only $\sim 20 \%$ of that in the PEDeN without applied voltage (Figure $\mathrm{S} 2 \mathrm{~b})$. Because less electrons transferred to the cathode, the nitrate and TN removal efficiencies were only $19.2 \pm 1.5 \%$ and $17.1 \pm 1.1 \%$, respectively (Figure $4 \mathrm{~b}, n=4$ ). By increasing the applied voltage, more electrons transferred to the cathode and resulted in the increase of nitrogen removal efficiency. At the applied voltage of $2.0 \mathrm{~V}$, the TN removal efficiency of EEDeN became comparable to that of PEDeN.

\section{DISCUSSION}

To date, denitrification driven by light has been verified in various photocatalytic or photoelectrochemical systems. However, most of the reported studies rely on additional chemical or energy input. For instance, organics are required as the hole scavengers in photocatalytic denitrification systems to reduce 
the recombination of photocarriers. ${ }^{27}$ This would obviously increase operation cost and may bring secondary pollution. In the case of many reported photoelectrochemical denitrification systems, the semiconductors were set as the photocathode and additional electric energy input is crucial to give a bias potential at the cathode. ${ }^{28}$ Although a recent study revealed the bias potential for photocathode can be imposed though coupling an acetate utilizing bioanode without electric energy input, the consumption of organics at the anode side would still fall in the limitation of additional chemicals dosing. ${ }^{20}$ Unlike these photoinduced denitrification systems, the photoelectrotrophic denitrification (PEDeN) system reported here was set by coupling the photoanode to an electrotrophic denitrification (EDeN) biocathode. Since the EDeN works at more positive potential than the flat-band potential of $\mathrm{TiO}_{2}$ (Figure 3c), the photoelectrons are capable of being separated spontaneously by the EDeN process. Meanwhile, the holes are consumed by water through oxygen evolution. In this way, the whole nitrate reduction process does not need the addition of organics and electric energy.

According to Figure $3 \mathrm{~b}$, the initial nitrate removal rate of PEDeN under $30 \mathrm{~mW} \cdot \mathrm{cm}^{-2} \mathrm{UV}$ illumination is calculated as $67.5 \pm 1.4 \mathrm{~g} \mathrm{NO}_{3}-\mathrm{N} \cdot \mathrm{m}^{-3} \cdot$ day $^{-1}(n=4)$. This value is lower than the well-known autohydrogenotrophic and autosulfurotrophic denitrification systems, ${ }^{3,29}$ in which the nitrate removal rates can be over $1 \mathrm{~kg} \mathrm{NO} \mathrm{NO}_{3}-\mathrm{N} \cdot \mathrm{m}^{-3} \cdot \mathrm{day}^{-1}$. However, the PEDeN system is more sustainable and environmentally friendly, because it avoids using risky (i.e., hydrogen gas) and environmentally unsafe (i.e., sulfur compounds) chemicals. Compared to the bioelectrochemistry associated denitrification system, the nitrate removal rate of PEDeN falls in the reported range $\left(45-500 \mathrm{~g} \mathrm{NO} \mathrm{NO}_{3}-\mathrm{N} \cdot \mathrm{m}^{-3} \cdot \mathrm{day}^{-1}\right)$ but is relatively low. ${ }^{8,30,31}$ The nitrate removal rate in a electrochemical system strongly correlates to the current. ${ }^{8}$ In this work, the current increase was observed when either enhancing the illumination intensity (Figure S1b, initial current increased $\sim 1.8$ times) or replacing the photoanode with the bioanode (under the organic sufficient condition, Figure S2b, initial current increased $\sim 2.3$ times), indicating the denitrification performance of the current PEDeN system is mainly limited by the photoanode. In fact, in this proof-of-concept of PEDeN, the size of the photoanode (surface area of $16 \mathrm{~cm}^{2}$ ) was much smaller than that of the cathode (projected area of $\sim 80 \mathrm{~cm}^{2}$ ), while the projected area of the anode and cathode in conventional denitrifying bioelectrochemical systems are usually equal. The photocurrent density observed in PEDeN system is calculated as $\sim 0.18 \mathrm{~mA}$ $\cdot \mathrm{cm}^{-2}$ (according to Figure $\mathrm{S} 1 \mathrm{~b}$, initial stage of the batch experiment, under $60 \mathrm{~mW} \cdot \mathrm{cm}^{-2} \mathrm{UV}$ illumination). This value is close to the current density $\left(\sim 0.2 \mathrm{~mA} \cdot \mathrm{cm}^{-2}\right.$ projected area of bioanode) reported in a high-performance denitrifying bioelectrochemical system with a nitrate removal rate up to $500 \mathrm{~g} \mathrm{NO}_{3}-\mathrm{N} \cdot \mathrm{m}^{-3} \cdot \mathrm{day}^{-1}{ }^{31}$ This result indicates the electrons providing capability by photoanode could have been comparable to the commonly used bioanode but were just limited by its smaller size in the present study. Configuration improvement by employing a larger photoanode is expected to significantly enhance the nitrate removal rate. Additionally, $\mathrm{TiO}_{2}$ photoanode prepared in the form of a nanotube array may further improve the denitrification performance, for this morphology could provide a higher surface area compared to the microstructured thin film prepared in this study and consequently would generate higher photocurrent. ${ }^{32}$ In addition to the improvement of photoanode side, the denitrification rate of the PEDeN system is also expected to be enhanced though performing internal circulation and controlling the $\mathrm{pH}$ at the cathode side, just like those reported in the conventional denitrifying bioelectrochemical systems. ${ }^{9,31}$

Thus far, the mechanism of EDeN is not been clear. It may involve complex redox protein systems for implementing the electron transfer from the cathode to the oxidized nitrogen compounds. The microbial denitrification go through four steps as $\mathrm{NO}_{3}^{-} \rightarrow \mathrm{NO}_{2}^{-} \rightarrow \mathrm{NO} \rightarrow \mathrm{N}_{2} \mathrm{O} \rightarrow \mathrm{N}_{2}$. The involved enzymes include nitrate reductase (Nar), nitrite reductase (Nir), Nitric oxide reductase (Nor), and nitrous oxide reductase $(\mathrm{Nos}) .{ }^{23}$ In some in vitro systems, the redox potentials of the active sites in these enzymes were determined. For instance, $\sim 200(\mathrm{pH}=7.14), 218(\mathrm{pH}=6), 320(\mathrm{pH}=7.6)$, and $60 \mathrm{mV}$ vs SHE ( $\mathrm{pH}=7.5)$ were reported in $\mathrm{Nar}$ (E. coli), Nir (E. coli), Nor ( $P$. denitrificans), and Nos ( $P$. pantotrophus), respectively. ${ }^{33-35}$ These redox potentials are positive to the cathodic potential in this work, indicating the electron transfer from the cathode to the key enzymes that implement denitrification is thermodynamically favorable and energy conservation of EDeN bacteria is consequently feasible. Compared to the abiotic electrochemical denitrification catalyzed by metals (e.g., $\mathrm{Cu}, \mathrm{Fe}$, and $\mathrm{Pt}$ ), in which the production of $\mathrm{NH}_{4}{ }^{+}$is difficult to be avoided, the EDeN process is particularly promising due to its highly selective transformation of $\mathrm{NO}_{3}^{-}$to $\mathrm{N}_{2}$. In addition, the observed onset potentials of nitrate reduction at metal electrodes are usually close to or even more negative than that of hydrogen evolution, ${ }^{36}$ whereas EDeN works at more positive potential. That means EDeN could gain the benefit of a high current efficiency without electrons being lost to the side hydrogen evolution reaction. In this study, the current efficiencies for denitrification were over 95\%, which is much higher than that usually observed in metal-catalyzed electrochemical systems $(<80 \%) .{ }^{36,37}$ Furthermore, since the flat-band potential of $\mathrm{TiO}_{2}$ is also close to that of hydrogen evolution. ${ }^{38}$ when the metal cathode is coupled with $\mathrm{a} \mathrm{TiO}_{2}$ photoanode, the electron transfer from the photoanode to the cathode would be ineffective. In a $\mathrm{TiO}_{2}$ photoanode/Pt cathode system, the denitrification rate was shown as about $5.3 \mathrm{~g} \mathrm{NO}_{3}-\mathrm{N} \cdot \mathrm{m}^{-3}$. day $^{-1}$ under $20 \mathrm{~mW} \cdot \mathrm{cm}^{-2} \mathrm{UV}$ illumination, ${ }^{39}$ which is much lower than that observed in PEDeN here.

Using solar energy to drive PEDeN is important to ensure that this technology is sustainable. The PEDeN in this study was preliminarily verified by using a $\mathrm{TiO}_{2}$ photoanode under $380 \pm 20 \mathrm{~nm}$ UV illumination. Since this wavelength is covered by the spectrum of sunlight, PEDeN is also expected to be worked under sunlight irradiation. However, the nitrate removal rate could be limited in the present PEDeN system because $\mathrm{TiO}_{2}$ merely responds to UV light (only accounts for $4 \%$ of the solar energy) due to the relatively large band gap $(\sim 3.2 \mathrm{eV}){ }^{17}$ Fortunately, many visible light response approaches, ${ }^{40}$ such as metal/nonmetal doping, dye sensitization, and coupling semiconductors, can help PEDeN work under the extended light spectrum. Further studies by employing these visible light responsive materials are therefore warranted to optimize this technology.

In addition to the technology aspect, PEDeN may also be important to gain further insight into the role of sunlight played in microbial nitrogen cycling, especially in certain natural minerals-enriched aqueous environment. Denitrification via bacteria receiving electrons from conductive magnetite has been reported in $T$. denitrificans. ${ }^{41}$ Besides the conductive mineral, a number of semiconductive minerals with sunlight 
response are also ubiquitous. When the conduction band potential is more negative than that of $\mathrm{EDeN}$, such as rutile, sphalerite, and hematite, ${ }^{11}$ PEDeN may occur with the help of these minerals, in which photoelectrons are produced by semiconductive minerals and transferred to the EDeN bacteria through the conductive material, similar to the technologically verified here. This might provide an alternative sunlightinvolved microbial denitrification pathway under organicslimiting condition other than the well-known microalgaebacteria system. ${ }^{42,43}$

\section{ASSOCIATED CONTENT}

\section{S Supporting Information}

The Supporting Information is available free of charge on the ACS Publications website at DOI: 10.1021/acs.est.7b02557.

Additional figures showing the denitrification kinetics as well as the profiles of current and electrode potentials in PEDeN system under various illumination intensities; current profiles of OEDeN and EEDeN systems (PDF)

\section{AUTHOR INFORMATION}

\section{Corresponding Author}

*Tel/Fax: +86-10-62915515. Email: ajwang@rcees.ac.cn. ORCID $\odot$

Ai-Jie Wang: 0000-0001-8868-5232

\section{Notes}

The authors declare no competing financial interest.

\section{ACKNOWLEDGMENTS}

We gratefully acknowledge the financial support by the National Natural Science Foundation of China (Grant Nos. 21407164 and 51508551), the Ministry of Environmental Protection of the People's Republic of China (Major Science and Technology Program for Water Pollution Control and Treatment, No. 2014ZX07204-005), and the Key Project of Chinese Academy of Sciences (No. ZDRW-ZS-2016-5).

\section{REFERENCES}

(1) Stevens, C. J.; Dise, N. B.; Mountford, J. O.; Gowing, D. J. Impact of nitrogen deposition on the species richness of grasslands. Science 2004, 303 (5665), 1876-1879.

(2) Ghafari, S.; Hasan, M.; Aroua, M. K. Bio-electrochemical removal of nitrate from water and wastewater - A review. Bioresour. Technol. 2008, 99 (10), 3965-3974.

(3) Karanasios, K. A.; Vasiliadou, I. A.; Pavlou, S.; Vayenas, D. V. Hydrogenotrophic denitrification of potable water: a review. J. Hazard. Mater. 2010, 180 (1-3), 20-37.

(4) Koenig, A.; Liu, L. H. Kinetic model of autotrophic denitrification in sulphur packed-bed reactors. Water Res. 2001, 35 (8), 1969-1978.

(5) Lee, K. C.; Rittmann, B. E. Applying a novel autohydrogenotrophic hollow-fiber membrane biofilm reactor for denitrification of drinking water. Water Res. 2002, 36 (8), 2040-2052.

(6) Lee, J. W.; Lee, K. H.; Park, K. Y.; Maeng, S. K. Hydrogenotrophic denitrification in a packed bed reactor: Effects of hydrogen-to-water flow rate ratio. Bioresour. Technol. 2010, 101 (11), 3940-3946.

(7) Prosnansky, M.; Sakakibara, Y.; Kuroda, M. High-rate denitrification and SS rejection by biofilm-electrode reactor (BER) combined with microfiltration. Water Res. 2002, 36 (19), 4801-4810.

(8) Clauwaert, P.; Rabaey, K.; Aelterman, P.; De Schamphelaire, L.; Pham, T. H.; Boeckx, P.; Boon, N.; Verstraete, W. Biological denitrification in microbial fuel cells. Environ. Sci. Technol. 2007, 41 (9), 3354-3360.
(9) Virdis, B.; Rabaey, K.; Yuan, Z.; Keller, J. Microbial fuel cells for simultaneous carbon and nitrogen removal. Water Res. 2008, 42 (12), $3013-3024$

(10) Xie, S.; Liang, P.; Chen, Y.; Xia, X.; Huang, X. Simultaneous carbon and nitrogen removal using an oxic/anoxic-biocathode microbial fuel cells coupled system. Bioresour. Technol. 2011, 102 (1), 348-354.

(11) Lianos, P. Production of electricity and hydrogen by photocatalytic degradation of organic wastes in a photoelectrochemical cell The concept of the Photofuelcell: A review of a re-emerging research field. J. Hazard. Mater. 2011, 185 (2-3), 575-590.

(12) Chen, X.; Mao, S. S. Titanium dioxide nanomaterials: Synthesis, properties, modifications, and applications. Chem. Rev. 2007, 107 (7), 2891-2959.

(13) Liu, G. S.; You, S. J.; Ma, M.; Huang, H.; Ren, N. Q. Removal of Nitrate by Photocatalytic Denitrification Using Nonlinear Optical Material. Environ. Sci. Technol. 2016, 50 (20), 11218-11225.

(14) Bems, B.; Jentoft, F. C.; Schlogl, R. Photoinduced decomposition of nitrate in drinking water in the presence of titania and humic acids. Appl. Catal., B 1999, 20 (2), 155-163.

(15) Hirayama, J.; Kondo, H.; Miura, Y. K.; Abe, R.; Kamiya, Y. Highly effective photocatalytic system comprising semiconductor photocatalyst and supported bimetallic non-photocatalyst for selective reduction of nitrate to nitrogen in water. Catal. Commun. 2012, 20, 99-102.

(16) Virdis, B.; Rabaey, K.; Yuan, Z. G.; Rozendal, R. A.; Keller, J. Electron Fluxes in a Microbial Fuel Cell Performing Carbon and Nitrogen Removal. Environ. Sci. Technol. 2009, 43 (13), 5144-5149.

(17) Wang, Q.; Xu, J. J.; Ge, Y. H.; Zhang, Y.; Feng, H. J.; Cong, Y. Q. Efficient nitrogen removal by simultaneous photoelectrocatalytic oxidation and electrochemically active biofilm denitrification. Electrochim. Acta 2016, 198, 165-173.

(18) Dong, S. S.; Zhang, X. Y.; He, F. R.; Dong, S. S.; Zhou, D. D.; Wang, B. Visible-light photocatalytic degradation of methyl orange over spherical activated carbon-supported and Er3+:YAlO3-doped $\mathrm{TiO} 2$ in a fluidized bed. J. Chem. Technol. Biotechnol. 2015, 90 (5), $880-887$.

(19) Cheng, Y.; Zhang, Y.; Shen, Q. X.; Gao, J.; Zhuang, G. Q.; Zhuang, X. L. Effects of exogenous short-chain $\mathrm{N}$-acyl homoserine lactone on denitrifying process of Paracoccus denitrificans. J. Environ. Sci. 2017, 54, 33-39.

(20) Lin, Z. Q.; Yuan, S. J.; Li, W. W.; Chen, J. J.; Sheng, G. P.; Yu, H. Q. Denitrification in an integrated bioelectro-photocatalytic system. Water Res. 2017, 109, 88-93.

(21) Carbonaro, S.; Sugihara, M. N.; Strathmann, T. J. Continuousflow photocatalytic treatment of pharmaceutical micropollutants: Activity, inhibition, and deactivation of $\mathrm{TiO} 2$ photocatalysts in wastewater effluent. Appl. Catal., B 2013, 129, 1-12.

(22) Srinivasan, V.; Weinrich, J.; Butler, C. Nitrite accumulation in a denitrifying biocathode microbial fuel cell. Environmental Science-Water Research \& Technology 2016, 2 (2), 344-352.

(23) Van Doan, T.; Lee, T. K.; Shukla, S. K.; Tiedje, J. M.; Park, J. Increased nitrous oxide accumulation by bioelectrochemical denitrification under autotrophic conditions: Kinetics and expression of denitrification pathway genes. Water Res. 2013, 47 (19), 7087-7097.

(24) Logan, B. E.; Hamelers, B.; Rozendal, R. A.; Schroder, U.; Keller, J.; Freguia, S.; Aelterman, P.; Verstraete, W.; Rabaey, K. Microbial fuel cells: Methodology and technology. Environ. Sci. Technol. 2006, 40 (17), 5181-5192.

(25) Virdis, B.; Rabaey, K.; Rozendal, R. A.; Yuan, Z. G.; Keller, J. Simultaneous nitrification, denitrification and carbon removal in microbial fuel cells. Water Res. 2010, 44 (9), 2970-2980.

(26) Lu, L.; Zeng, C. P.; Wang, L. D.; Yin, X. B.; Jin, S.; Lu, A. H.; Ren, Z. J. Graphene oxide and H-2 production from bioelectrochemical graphite oxidation. Sci. Rep. 2015, 5, 16242.

(27) Doudrick, K.; Yang, T.; Hristovski, K.; Westerhoff, P. Photocatalytic nitrate reduction in water: Managing the hole scavenger and reaction by-product selectivity. Appl. Catal., B 2013, 136-137, 4047. 
(28) Sayao, F. A.; Nunez, L.; Zanoni, M. V. B. Efficient Photoelectrochemical Reduction of Nitrite to Ammonium and Nitrogen Containing Gaseous Species Using Ti/TiO2 Nanotube Electrodes. J. Braz. Chem. Soc. 2014, 25 (7), 1153-1160.

(29) Shao, M. F.; Zhang, T.; Fang, H. H. P. Sulfur-driven autotrophic denitrification: diversity, biochemistry, and engineering applications. Appl. Microbiol. Biotechnol. 2010, 88 (5), 1027-1042.

(30) Huang, X.; Xie, S.; Liang, P.; Chen, Y.; Xia, X. Simultaneous carbon and nitrogen removal using an oxic/anoxic-biocathode microbial fuel cells coupled system. Bioresour. Technol. 2011, 102 (1), 348-354.

(31) Clauwaert, P.; Desloover, J.; Shea, C.; Nerenberg, R.; Boon, N.; Verstraete, W. Enhanced nitrogen removal in bio-electrochemical systems by $\mathrm{pH}$ control. Biotechnol. Lett. 2009, 31 (10), 1537-1543.

(32) Xie, Y. B. Photoelectrochemical application of nanotubular titania photoanode. Electrochim. Acta 2006, 51 (17), 3399-3406.

(33) Gronberg, K. L. C.; Roldan, M. D.; Prior, L.; Butland, G.; Cheesman, M. R.; Richardson, D. J.; Spiro, S.; Thomson, A. J.; Watmough, N. J. A low-redox potential heme in the dinuclear center of bacterial nitric oxide reductase: Implications for the evolution of energy-conserving heme-copper oxidases. Biochemistry 1999, 38 (42), $13780-13786$.

(34) Rasmussen, T.; Brittain, T.; Berks, B. C.; Watmough, N. J.; Thomson, A. J. Formation of a cytochrome c-nitrous oxide reductase complex is obligatory for $\mathrm{N} 2 \mathrm{O}$ reduction by Paracoccus pantotrophus. Dalton Trans. 2005, 21, 3501-3506.

(35) Guigliarelli, B.; Asso, M.; More, C.; Augier, V.; Blasco, F.; Pommier, J.; Giordano, G.; Bertrand, P. Epr and Redox Characterization of Iron-Sulfur Centers in Nitrate Reductases-a and Reductases$\mathrm{Z}$ from Escherichia-Coli - Evidence for a High-Potential and a LowPotential Class and Their Relevance in the Electron-Transfer Mechanism. Eur. J. Biochem. 1992, 207 (1), 61-68.

(36) Li, M.; Feng, C. P.; Zhang, Z. Y.; Sugiura, N. Efficient electrochemical reduction of nitrate to nitrogen using $\mathrm{Ti} / \mathrm{IrO} 2-\mathrm{Pt}$ anode and different cathodes. Electrochim. Acta 2009, 54 (20), 46004606.

(37) Zhang, Z. Q.; Xu, Y. P.; Shi, W. X.; Wang, W.; Zhang, R. J.; Bao, X.; Zhang, B.; Li, L.; Cui, F. Y. Electrochemical-catalytic reduction of nitrate over $\mathrm{Pd}-\mathrm{Cu} /$ gamma $\mathrm{Al} 2 \mathrm{O} 3$ catalyst in cathode chamber: Enhanced removal efficiency and N-2 selectivity. Chem. Eng. J. 2016, 290, 201-208.

(38) Radecka, M.; Rekas, M.; Trenczek-Zajac, A.; Zakrzewska, K. Importance of the band gap energy and flat band potential for application of modified $\mathrm{TiO} 2$ photoanodes in water photolysis. $J$. Power Sources 2008, 181 (1), 46-55.

(39) Saito, R.; Ueno, H.; Nemoto, J.; Fujii, Y.; Izuoka, A.; Kaneko, M. Photoelectrochemical conversion of NO3- to N-2 by using a photoelectrochemical cell composed of a nanoporous $\mathrm{TiO} 2$ film photoanode and an O-2 reducing cathode. Chem. Commun. 2009, 22, 3231-3233.

(40) Pelaez, M.; Nolan, N. T.; Pillai, S. C.; Seery, M. K.; Falaras, P.; Kontos, A. G.; Dunlop, P. S. M.; Hamilton, J. W. J.; Byrne, J. A.; O'Shea, K.; Entezari, M. H.; Dionysiou, D. D. A review on the visible light active titanium dioxide photocatalysts for environmental applications. Appl. Catal., B 2012, 125, 331-349.

(41) Kato, S.; Hashimoto, K.; Watanabe, K. Microbial interspecies electron transfer via electric currents through conductive minerals. Proc. Natl. Acad. Sci. U. S. A. 2012, 109 (25), 10042-10046.

(42) Sorensen, J.; Jorgensen, T.; Brandt, S. Denitrification in Stream Epilithon - Seasonal-Variation in Gelbaek and Rabis-Baek, Baek, Denmark. FEMS Microbiol. Lett. 1988, 53 (6), 345-353.

(43) de Smet, W. H.; Evens, F. M. The influence of light and air on the purification of polluted water. Hydrobiologia 1970, 35 (3-4), 494544. 